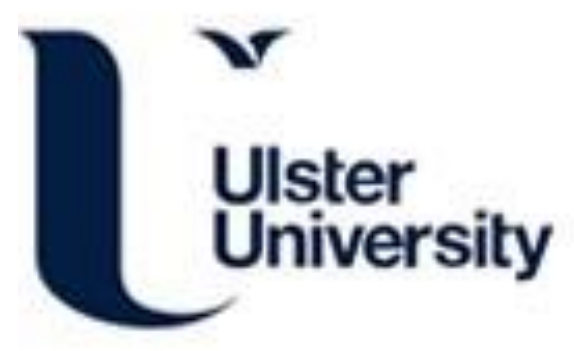

\title{
A novel system for tracking iron golf clubheads
}

Corke, T. W., Betzler, N. F., Wallace, E. S., \& Otto, S. R. (2019). A novel system for tracking iron golf clubheads. Proceedings of the Institution of Mechanical Engineers, Part P: Journal of Sports Engineering and Technology, 233(1), 59-66. https://doi.org/10.1177/1754337118792798

Link to publication record in Ulster University Research Portal

\section{Published in:}

Proceedings of the Institution of Mechanical Engineers, Part P: Journal of Sports Engineering and Technology

Publication Status:

Published (in print/issue): 01/03/2019

DOI:

10.1177/1754337118792798

\section{Document Version}

Author Accepted version

\section{General rights}

Copyright for the publications made accessible via Ulster University's Research Portal is retained by the author(s) and / or other copyright owners and it is a condition of accessing these publications that users recognise and abide by the legal requirements associated with these rights.

\section{Take down policy}

The Research Portal is Ulster University's institutional repository that provides access to Ulster's research outputs. Every effort has been made to ensure that content in the Research Portal does not infringe any person's rights, or applicable UK laws. If you discover content in the Research Portal that you believe breaches copyright or violates any law, please contact pure-support@ulster.ac.uk. 


\section{A novel system for tracking iron golf clubheads}

\begin{tabular}{|c|c|}
\hline Journal: & Part P: Journal of Sports Engineering and Technology \\
\hline Manuscript ID & JSET-17-0030.R4 \\
\hline Manuscript Type: & Original Article \\
\hline Date Submitted by the Author: & 04-Jun-2018 \\
\hline Complete List of Authors: & $\begin{array}{l}\text { Corke, Tom; The R\&A, Equipment Standards } \\
\text { Betzler, Nils; The R\&A, Equipment Standards; Qualisys AB, Development } \\
\text { Wallace, Eric; Ulster University, Sport and Exercise Sciences } \\
\text { Otto, Steve; The R\&A, Equipment Standards }\end{array}$ \\
\hline Keywords: & motion capture, golf, iron, clubhead presentation, golf robot, impact \\
\hline Abstract: & $\begin{array}{l}\text { The importance of iron play to scoring in golf is widely recognised. To } \\
\text { better understand this relationship, accurate, yet unobtrusive } \\
\text { measurement techniques are required to capture information about the } \\
\text { collision between the golf club and ball. This article presents a method for } \\
\text { tracking an iron clubhead prior to impact with the ball. Using repeated } \\
\text { shots by a golf robot with a } 5 \text {-iron and } 9 \text {-iron, the system reliably } \\
\text { measured clubhead speed }(S D \leq 0.5 \mathrm{mph}) \text {, face angle }\left(\leq 0.2^{\circ}\right) \text {, club path } \\
\left(\leq 0.2^{\circ}\right) \text {, effective loft }\left(\leq 0.5^{\circ}\right) \text {, attack angle }\left(\leq 0.1^{\circ}\right) \text { and effective lie } \\
\left(\leq 0.3^{\circ}\right) \text {. Impact position was within a SD } \leq 0.6 \mathrm{~mm} \text { for repeated shots. } \\
\text { Absolute accuracy of horizontal impact position at initial contact was }<1 \\
\text { mm, whereas a systematic offset of up to } 4 \mathrm{~mm} \text { was found for vertical } \\
\text { impact position compared to tests using impact location tape. This offset } \\
\text { was dependent on the loft of the club and could be explained by the } \\
\text { interaction between ball and club during contact. Additionally, a unique } \\
\text { feature of the algorithm is presented which categorises impacts commonly } \\
\text { known as 'top', 'thin', 'good' or 'heavy' shots, which is facilitated through } \\
\text { tracking of the bottom edge of the clubhead using virtual markers. Hence, } \\
\text { this tracking system is presented as a novel solution to accurately measure } \\
\text { clubhead presentation and initial ball impact location for irons. }\end{array}$ \\
\hline
\end{tabular}

\section{SCHOLARONE}

Manuscripts 
Original Article

Corresponding author:

Steve R. Otto, R\&A Rules Ltd, The R\&A, Research and Testing, Allan Robertson House, Kingsbarns Golf Links, St Andrews, UK

Email: SteveOtto@,RandA.org

\title{
A novel system for tracking iron golf clubheads
}

\author{
Tom W. Corke ${ }^{\mathrm{a}, \mathrm{b}}$, Nils F. Betzler ${ }^{\mathrm{b}, \mathrm{c}}$, Eric S. Wallace ${ }^{\mathrm{a}}$, Steve R. \\ $\mathrm{Otto}^{\mathrm{b}}$
}

${ }^{\mathrm{a}}$ Sport and Exercise Sciences Research Institute, Ulster University, Northern Ireland

${ }^{\mathrm{b}}$ R\&A Rules Ltd, St Andrews, Scotland

${ }^{\mathrm{c}}$ Qualisys AB, Gothenburg, Sweden

\section{Abstract}

The importance of iron play to scoring in golf is widely recognised. To better understand this relationship, accurate, yet unobtrusive measurement techniques are required to capture information about the collision between the golf club and ball. This article presents a method for tracking an iron clubhead prior to impact with the ball. Using repeated shots by a golf robot with a 5-iron and 9-iron, the system reliably measured clubhead speed $(\mathrm{SD} \leq 0.5 \mathrm{mph})$, face angle $\left(\leq 0.2^{\circ}\right)$, club path $\left(\leq 0.2^{\circ}\right)$, effective loft $\left(\leq 0.5^{\circ}\right)$, attack angle $\left(\leq 0.1^{\circ}\right)$ and effective lie $\left(\leq 0.3^{\circ}\right)$. Impact position was within a SD $\leq$ $0.6 \mathrm{~mm}$ for repeated shots. Absolute accuracy of horizontal impact position at initial contact was $<1 \mathrm{~mm}$, whereas a systematic offset of up to $4 \mathrm{~mm}$ was found for vertical impact position compared to tests using impact location tape. This offset was dependent on the loft of the club and could be explained by the interaction between ball and club during contact. Additionally, a unique feature of the algorithm is presented which categorises impacts commonly known as 'top', 'thin', 'good' or 'heavy' shots, which is facilitated through tracking of the bottom edge of the clubhead using virtual markers. Hence, this tracking system is presented as a novel solution to accurately measure clubhead presentation and initial ball impact location for irons.

\section{Keywords}

motion capture, golf, iron, clubhead presentation, impact, golf robot 


\section{Introduction}

Recent statistical research has suggested that tee-to-green play has previously been underestimated, relative to putting, in terms of its importance to scoring. ${ }^{1}$ When considering the established relationship between the length of a putt and the probability of holing it, ${ }^{3,4}$ it is perhaps unsurprising that the resulting proximity to the hole of approach shots with irons has such a large bearing on overall performance. Furthermore, shots to the green from outside 100 yards have been shown to be more indicative of a golfer's average score, than either putting, approach shots inside 100 yards, or driving. ${ }^{2}$ Contrasting the importance of approach play with the general lack of research involving irons clearly justifies the need for a better understanding of the club and ball impact conditions for irons.

The initial launch conditions of a shot are determined by the orientation and velocity of the clubhead at impact and the ball characteristics. Clubhead presentation can be considered as a set of input variables, whilst the initial ball launch conditions are the primary set of outcome variables (resultant motion of the clubhead being secondary). Although several effective, commercially available methods exist for measuring ball launch conditions, reliable and uncompromising techniques for precisely measuring clubhead presentation at ball impact have not received much scientific attention.

The key issue in tracking the clubhead during the golf swing is maintaining the validity of the method without creating undesirable effects because of the measurement 
technique. For example, applying tape or spray to the club face provides reliable indications of impact position, but is likely to compromise the validity of certain ball launch variables, such as spin. Instrumenting clubheads is also difficult given the highly dynamic nature of the golf swing and relatively small surface area of the clubhead, particularly for irons. Early attempts at less intrusive methodologies employed passivemarker motion tracking, using calibration trials to enable a virtual club face to be reconstructed in each frame using spatial relationships with tracking markers situated away from the face. ${ }^{5}$ Due to the fact that not all of the tracking markers were located on the clubhead, their relationship with the calibration markers may have been affected. More recent efforts with both irons ${ }^{6}$ and drivers ${ }^{7}$ adhered all tracking markers to the clubhead, however the sampling frequencies used $(400-480 \mathrm{~Hz})$ could be considered too low due to the need to extrapolate forwards from the final frame before impact. A previous study by our group reported measurements at much higher frequencies (1000 $\mathrm{Hz}$ ) and unobtrusive marker placement for driver shots. ${ }^{8}$ The same system was previously trialled for 9-iron shots, ${ }^{9}$ but the adaptation of the system for tracking iron clubheads was not described in detail.

Thus, the aim of this study was to develop an unobtrusive and reliable system to characterise iron clubhead presentation variables at ball impact.

\section{Developments to Driver System for Use with Irons}

The overall data collection procedure remained essentially unchanged to that previously outlined for drivers ${ }^{8}$ as described below. Opto-reflective markers adhered to the clubhead were tracked prior to impact by three Oqus 300+ cameras (Qualisys AB, Gothenburg, 
Sweden) as shown in Fig. 1. The cameras captured the coordinate data at $1000 \mathrm{~Hz}$ using ten frames prior to impact for analysis. Given that the impact event typically occurs between frames, the trajectory of the virtual club face was extrapolated from the last preimpact frame to establish a precise impact time. No filters were applied to the coordinate data. A transformation matrix, generated prior to testing using a set of calibration markers, established the relationship between the club face and the tracking markers. Positions of the virtual club face markers at impact were used to determine the impact location. The club face normal at this event was used to determine face angle, effective loft and effective lie, whilst the trajectory of the tracking markers was used to derive clubhead speed, club path and attack angle.

\section{Tracking Markers}

The changes made to the driver tracking system to accommodate irons were primarily due to differences in clubhead geometry. As shown on Fig. 2, tracking markers for irons were configured such that two were located on the top-line of the clubhead (toe and heel with diameter $4 \mathrm{~mm}$ ) and one was located on the hosel (diameter of $8 \mathrm{~mm}$ ), whereas for drivers, all three tracking markers were adhered to the crown of the clubhead. Ball position was identified in the same way as for drivers: a tape marker applied to the top most point (or 'north pole') of the ball, with the centre of the ball defined as the radius of the ball from this marker in the negative global Z-direction (i.e. vertically downwards). 

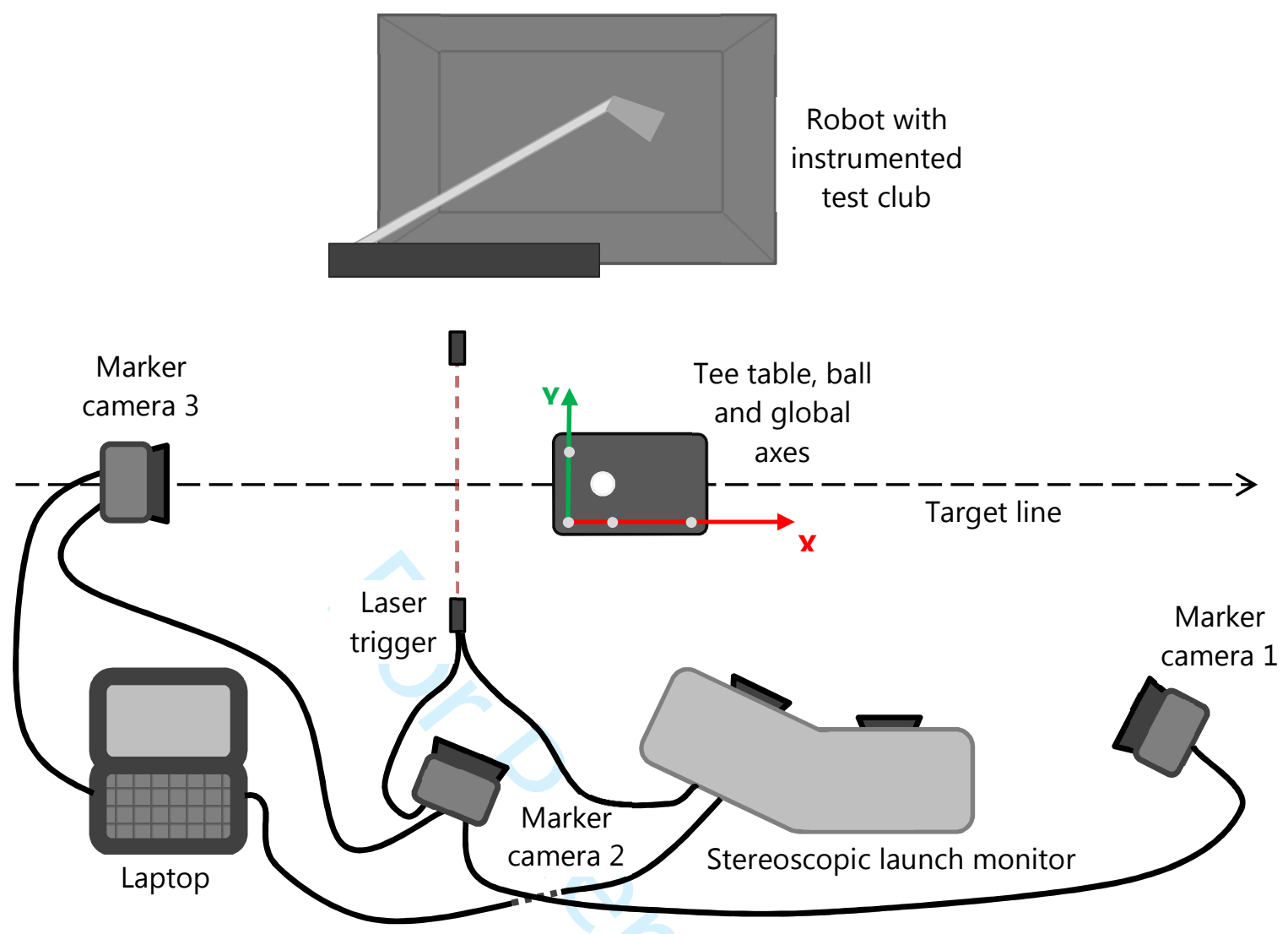

Figure 1: Schematic diagram of experimental setup and camera placement for robot testing.

Cameras positioned on fixtures at a height of approximately $3.5 \mathrm{~m}$. Global Z-axis (not pictured) pointed vertically upwards. For outdoor player testing, cameras were mounted on tripods in a similar configuration, but at a height of approximately $2 \mathrm{~m}$. 


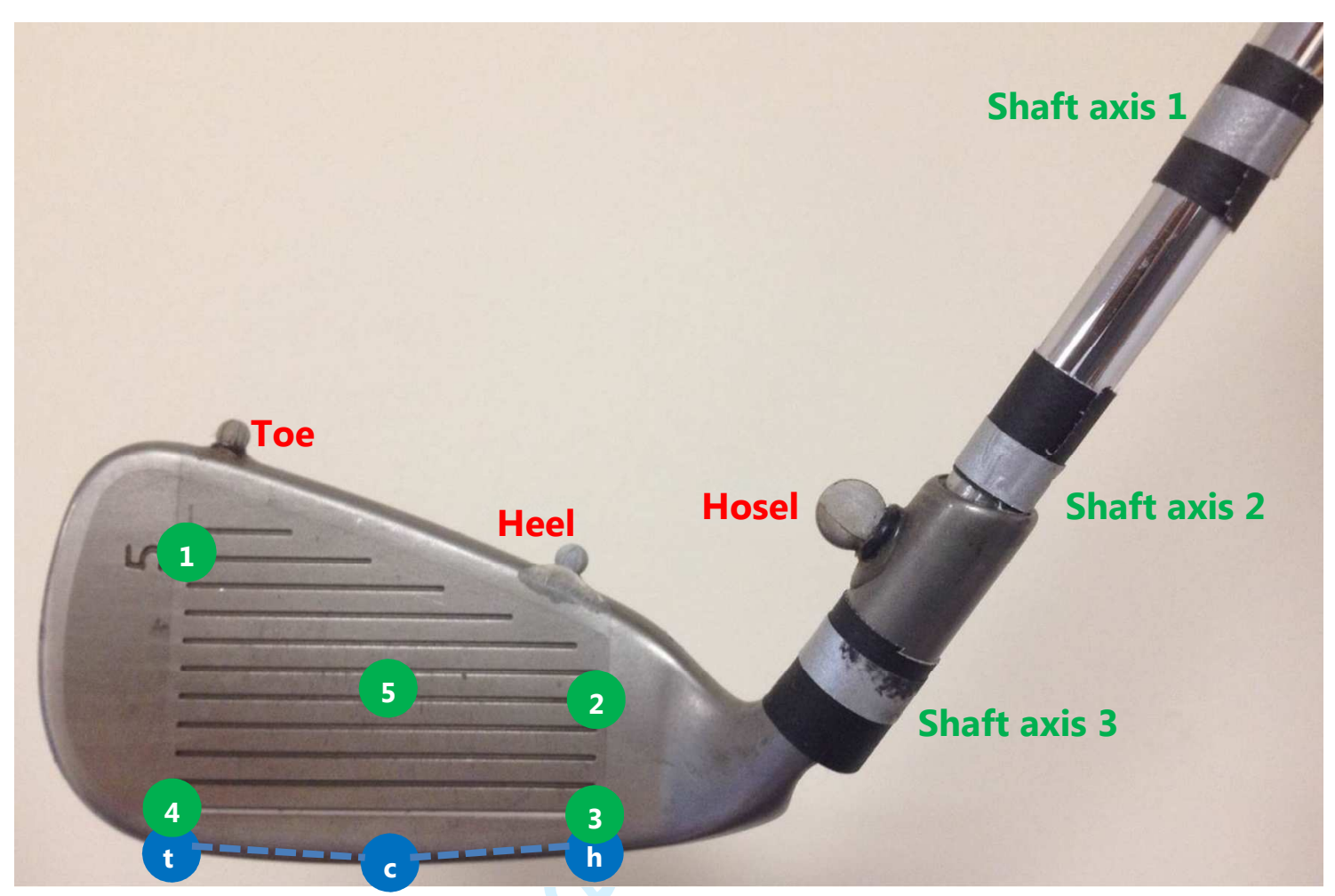

Figure 2: Marker placement on clubhead and hosel.

Tracking markers (red lettering) and calibration markers (green). Virtual markers and representation of the leading edge (dashed line) are also shown (blue).

\section{Calibration Markers}

The location of the five club face calibration markers (diameter of $4 \mathrm{~mm}$ ) remained essentially the same for irons as for drivers as shown on Fig. 2, however, given the absence of bulge and roll (i.e. a convex face) on irons, a plane was fitted as a virtual reconstruction of the club face. In addition, three markers (diameter of $4 \mathrm{~mm}$ ) were placed on the leading edge of the iron, as shown in blue on Fig. 2, to represent the leading edge of the club face. These markers can be added virtually relative to the lowest groove on the club face, between calibration markers 3 and 4 . The system defines the impact as the point at which the plane (or surface, in the case of drivers) of the face first intersects 
the surface of the virtual ball (i.e. one ball radius from the ball centre). If the impact point is within the boundaries of the club face, this is likely to be a valid representation of impact, however, should the clubhead miss the ball, this plane will still intersect the ball surface (e.g. when it passed above the ball). Attempts outlined below have been made to make the system more robust in this regard.

\section{Centre of Gravity Measurement}

\section{Rationale}

Another issue with previous attempts at clubhead tracking is the somewhat arbitrary nature of the measurement point at which velocity-based parameters, such as clubhead speed, club path and attack angle, are calculated as shown on Fig. 3. Some studies used the face centre as a measurement point, ${ }^{5-7}$ whilst others average the velocities of the three tracking markers to calculate these parameters. ${ }^{8}$ Since the relationship between impact location and centre of gravity (CG) location is critical when considering impact phenomena such as the gear effect and initial ball direction, ${ }^{10,11}$ neither of these approaches are particularly relevant when considering the physics of the impact between ball and club, nor are they likely to offer much consistency between systems or clubheads of varying geometry. As such, it was decided that constructing a virtual CG location, relative to the tracking markers, would yield more relevant and robust measures of these velocity-based clubhead presentation variables. Additionally, transforming this CG location into the club face coordinate system will provide the impact location measurements with a physically relevant reference point. It is noted that this novel CG method can be used to track any location associated with the clubhead. 


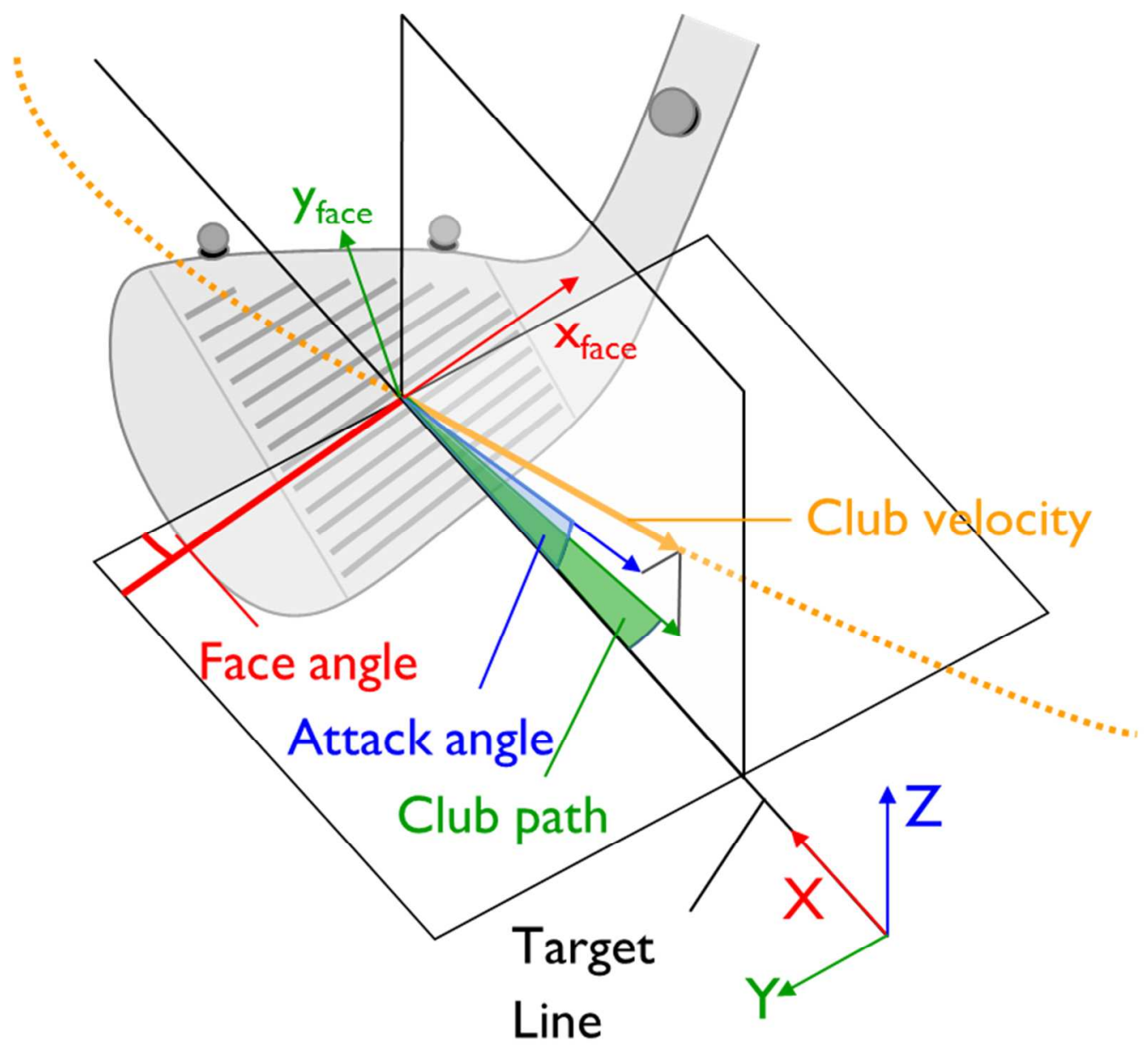

Figure 3: Conventions for clubhead velocity, attack angle and club path based on the motion of the CG relative to the global coordinate system.

Face angle and effective loft are calculated using the relative position of face and global coordinate systems at impact.

\section{Measurement and Conversion of Clubhead Centre of Gravity Location}

To determine the location of this virtual CG, an Auditor CGM (Technorama Co. Ltd., Taliao, Taiwan) was used. This device mounts the clubhead in various orientations relative to a fulcrum in order to determine the distance of a clubhead's CG along each of three orthogonal axes, with the origin at the centre of the opening to the hosel as shown on Fig. 3. The z-axis of this hosel coordinate system runs along the centreline of the hosel. The $\mathrm{x}-$ 
axis is perpendicular to the z-axis and parallel to the plane of the club face, with the yaxis completing the right-hand coordinate system.

In order to transfer this information into the clubhead tracking system, the same hosel coordinate system had to be created within the model of the clubhead. Three additional calibration markers were attached to the club shaft and hosel using $6.5 \mathrm{~mm}$ wide optoreflective tape as shown on Fig. 2, and were used to define the z-axis of the hosel coordinate system. The middle of these three markers was located on the shaft immediately above the hosel (or ferrule, should one be present), from which an offset could be applied to define the origin of the hosel coordinate system. The orientation of the hosel coordinate system, relative to the face coordinate system, was determined based on the loft and lie of the club. These were determined using the motion capture system as described in the following section. Converting the CG location as measured using the Auditor CGM into the face coordinate system enables creation of a virtual clubhead CG location.

\section{Static Loft and Lie Measurement}

For conversions between the face and hosel coordinate systems, it was necessary to determine the orientation of the shaft axis relative to the club face, commonly referred to as the loft and lie of the club. First, the location of the shaft axis in the calibration trial was determined by fitting a line through the three reference markers on the shaft axis as 
shown on Fig. 2. Then, loft and lie were based on the orientation of the shaft axis relative to the face coordinate system, expressed in radians in Eqs. (1) and (2),

$$
\begin{gathered}
\theta_{\text {lie }}=\arccos \frac{\vec{s} \cdot[-1,0,0]}{|\vec{s}|} \\
\theta_{\text {loft }}=\arccos \frac{\vec{s}_{\text {proj }} \cdot[0,-1,0]}{\left|\vec{s}_{\text {proj }}\right|}
\end{gathered}
$$

where $\vec{s}$ is the shaft axis vector expressed in the face coordinate system, and $\vec{s}_{\text {proj }}$ is the projection of the shaft axis vector onto the $y-z$ plane of face coordinate system as shown on Fig. 4. Resulting measurements of static loft and lie for the two test clubs are shown in Table 1.

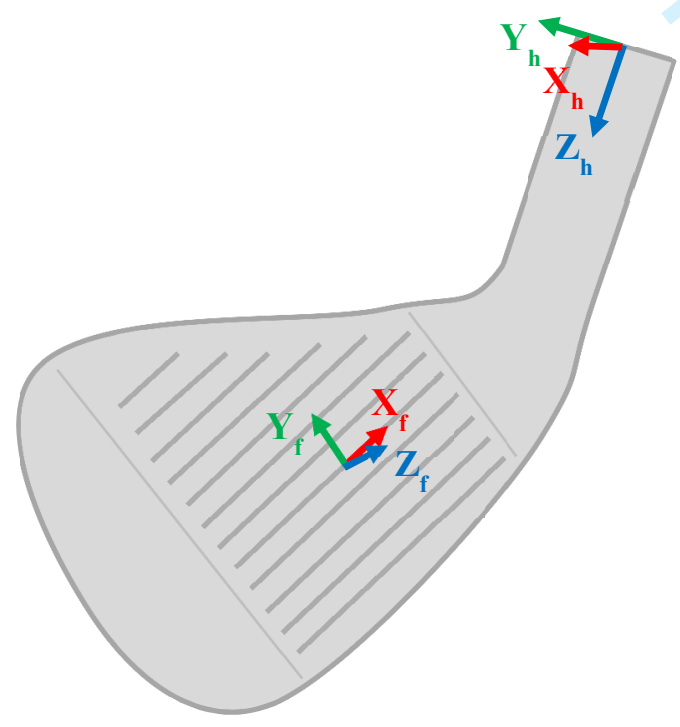

Figure 4: Hosel and face coordinate systems. 


\section{Leading Edge Tracking}

Table 1: Loft and lie of irons used in this study as measured by the clubhead tracking system.

\begin{tabular}{lll}
\hline Club & Loft & Lie \\
\hline 5-iron & 24.3 & 59.5 \\
9-iron & 40.5 & 62.2 \\
\hline
\end{tabular}

A fundamental difference between driver and iron shots is that the former are predominantly hit with the ball resting on a tee-peg, whilst the latter are more often hit from the surface of the turf. As a result, a much higher probability exists that the clubhead will come in contact with the ground around the time of impact. An indication of the height of the clubhead's 'leading edge' (essentially the lower limit of the club face) at impact would be valuable and provide insight into the nature of impact, or 'strike', between club and ball. These data would also assist, to some extent, in overcoming the issue with the infinite plane of the club face erroneously intersecting the ball, as discussed previously.

Distances in the face coordinate system y-direction were measured from each end and the centre of the bottom groove to the leading edge, which enabled three virtual markers to be created as shown on Fig. 2. The leading edge of the tested irons was in fact slightly curved, however it was deemed that straight lines between these markers $(\mathrm{t}$ and $\mathrm{c} ; \mathrm{c}$ and h) offered a sufficiently accurate representation of the leading edge at this stage of development. The discrepancy between the straight lines and the actual leading edge was less than $0.5 \mathrm{~mm}$. 


\section{Strike Classification}

Table 2 and Fig. 5 present definitions used amongst the golfing community including 'top', 'thin' and 'good' to describe ball striking classification. Shots were categorised as 'heavy' if any of the virtual markers at the leading edge were below the ground at impact as shown on Fig. 6.

Table 2: Strike classification ${ }^{1}$.

\begin{tabular}{ll}
\hline Classification & Definition \\
\hline 'Top' & $\begin{array}{l}\text { Leading edge point above the ball centre by less than one ball } \\
\text { radius }\end{array}$ \\
Leading edge point above tangent to ball but below ball \\
'Thin'
\end{tabular}


Figure 5: Strike classification based on leading edge height at impact, as viewed in the global X-Z plane.

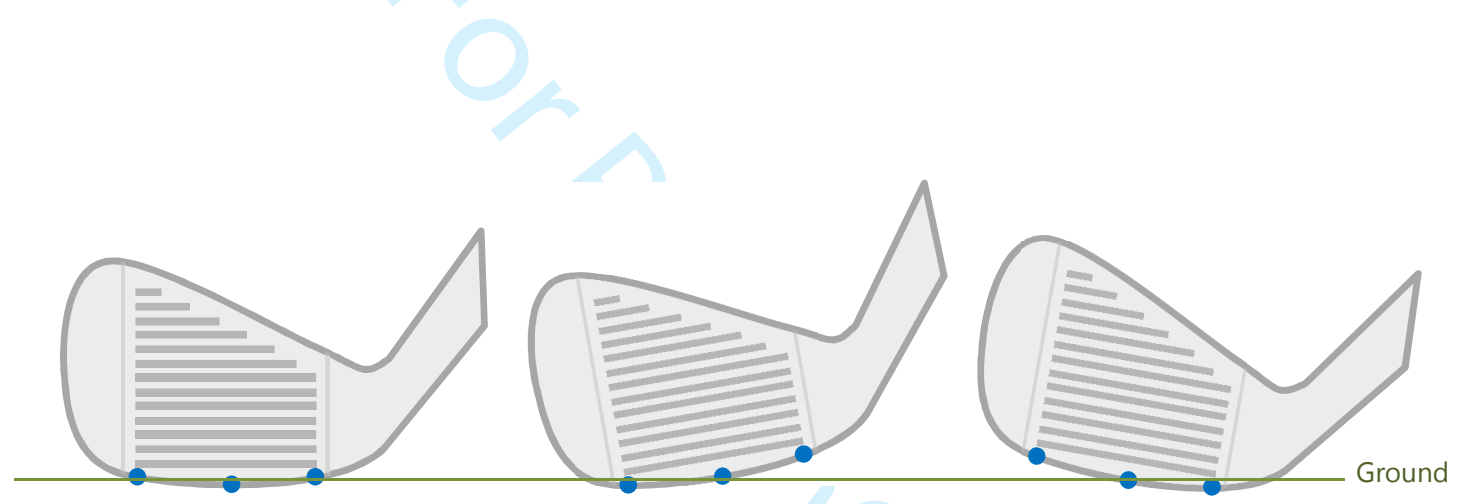

Figure 6: Additional conditions for heavy shot

Any of the three virtual markers representing the leading edge were below the ground at impact.

\section{Validation of Impact Location Measurement}

The system on which these developments are based had previously been validated for use with drivers, with spatial and temporal accuracy of the underlying motion capture system also having been reported. ${ }^{8}$ The adaptations to the marker set, combined with the updated algorithm and additional shot characterisation, necessitated a re-validation of the system. A golf robot was used to swing a 5-iron (static loft: $26^{\circ}$ ) and a 9-iron (static loft: $42^{\circ}$ ) in a highly repeatable manner, whilst impact location was systematically varied. This protocol enabled measurements obtained from the clubhead tracking system to be compared to the 
manually measured location of the imprint left on the club face, on a shot-by-shot basis. In order to gauge an indication of the repeatability of this setup, descriptive statistics for clubhead speed measured by the same clubhead tracking system have previously been reported for sets of forty driver swings performed by the robot at four nominal clubhead speeds ${ }^{8}$. This method does not enable distinction between variance attributable to the robot and that of the measurement system. As the application of this tape to the face is likely to influence launch conditions, twelve shots were performed without tape at the beginning of the test with each club. This was to establish a baseline set of clubhead presentation and ball launch characteristics for the impact location that was aligned with the $\mathrm{CG}$ in the face coordinate system.

\section{Method}

The motion tracking cameras were set up as described above and as shown in Fig. 1. The 5-iron was first mounted in the robot and the physical pose of the robot was adapted until the face angle was square to the club path (marker-based) at impact, the grooves were horizontal, and the impact location (as measured by the clubhead tracking system) was aligned with the location of the clubhead CG in the face coordinate system. The robot control parameters were then refined (face square to path, effective lie and impact location were maintained) so that the launch conditions generated were representative of a 5-iron shot of an elite amateur golfer. ${ }^{12}$ Once this had been achieved, twelve consecutive shots were performed to establish reference launch conditions as shown on Table 3. The club face was cleaned and dried between each of these twelve shots to avoid a build-up of cover material affecting launch conditions. Following this, masking tape was applied to the clubface and the same shot was performed. After the shot, the distance 
from the centre of the ball 'imprint' to the origin of the face coordinate system (i.e. the geometric centre of the sandblasted area of the club face) in $\mathrm{x}$ and $\mathrm{y}$ directions was measured. The tape was then removed and replaced with a fresh piece of tape for the subsequent shot. This process was repeated for six shots at each of six impact locations. Impact locations were varied only in the y-direction, with the $\mathrm{x}$-value being held constant at the $\mathrm{CG}$ x-location in the face coordinate system. The y-values of the impact locations were varied in $3 \mathrm{~mm}$ increments: $+6,+3,0,-3,-6$ and $-9 \mathrm{~mm}$ in the y-direction as measured by the clubhead tracking system, relative to the clubhead CG location. The process was then repeated for the 9-iron. The physical pose of the robot had to be adjusted to accommodate the 9-iron's steeper lie angle and shorter shaft, however the same robot control parameters were used as for the 5-iron. The imprint left by the ball at all measured impact locations was wholly on the face for both clubs.

Twelve premium, commercially available, urethane-covered golf balls were used for the testing and rotated in sequence to minimise any effect of ball variation. A portable stereoscopic launch monitor (Foresight Sports, San Diego, CA) was used to measure ball launch conditions, and the described clubhead tracking system was used to monitor clubhead presentation and measure impact location.

\section{Results}

Table 3 shows descriptive statistics for both sets of launch conditions. The launch conditions for the 5-iron closely represent previously reported elite amateur launch conditions. ${ }^{12}$ The same robot control parameters were used for the 9-iron for test consistency. Ball position was changed to elicit similar launch conditions representative 
of elite amateur performance with the 9 -iron club, ${ }^{9}$ however the reference robot shot produced a slightly greater magnitude of spin and higher launch angle relative to these elite player averages. Table 4 shows the associated clubhead presentation parameters for these reference shots.

Table 3: Mean and standard deviation (SD) ball launch characteristics for shots without tape $(\mathrm{n}=12)^{1}$.

\begin{tabular}{llllllll}
\hline & $\begin{array}{l}\text { Ball } \\
\text { speed } \\
\text { (mph) }\end{array}$ & $\begin{array}{l}\text { Efficiency } \\
\text { (no } \\
\text { units) }\end{array}$ & $\begin{array}{l}\text { Efficiency } \\
\text { CG } \\
\text { (no } \\
\text { units) }\end{array}$ & $\begin{array}{l}\text { Vert. } \\
\text { launch } \\
\text { angle }\end{array}$ & $\begin{array}{l}\text { Horiz. } \\
\text { launch } \\
\text { angle }\end{array}$ & $\begin{array}{l}\text { Total } \\
\text { spin } \\
\text { (rpm) }\end{array}$ & $\begin{array}{c}\text { Spin } \\
\text { axis }\end{array}$ \\
\hline 5-iron & & & & & & \\
\hline Mean & 127.59 & 1.444 & 1.401 & 16.43 & 2.90 & 5157 & -3.37 \\
SD & 0.41 & 0.005 & 0.009 & 0.16 & 0.38 & 129 & 1.82 \\
\hline 9-iron & & & & & & & \\
\hline Mean & 104.91 & 1.232 & 1.199 & 26.56 & 5.05 & 9226 & -2.78 \\
SD & 0.49 & 0.006 & 0.007 & 0.23 & 0.32 & 219 & 0.82 \\
\hline
\end{tabular}

${ }^{1}$ Impact location was aligned with the CG in the face coordinate system. Both CG- and markerbased measurements (average of the three tracking markers) have been presented for efficiency (defined as ball speed divided by clubhead speed). All values in degrees $\left(^{\circ}\right)$ unless stated otherwise.

The clubhead presentation results in Table 4 demonstrate the differences between the velocity-based measurements (namely clubhead speed, attack angle and club path) when their calculation is based on the virtual clubhead $\mathrm{CG}$ location relative to an average of tracking marker locations, or indeed any other location. For the 9-iron utilised in this study, the marker-based values for club path and attack angle are almost identical, however for the 5-iron, the magnitude of these variables at impact appear to be 
underestimated by the marker-based calculations. Clubhead speed is more grossly underestimated relative to the speed at the CG for both clubs. Calculations show that a difference of $25 \mathrm{~mm}$ in the location of the CG and the average of the markers at a closing rate of $2500 \%$ s would predict a difference of $2.4 \mathrm{mph} .{ }^{15}$ Should CG-based measurement of these parameters be unavailable to future research studies, deriving values based on averages of the markers (in this configuration) offers a reasonable approximation of the trajectory of the clubhead at impact. However, as noted above, this method underestimates clubhead speed, most likely due to the marker positions being biased towards the heel, so using the mean of the heel and toe markers may be more appropriate. The CG-based measures obviously remain preferable, since they are physically relevant. Additionally, removing measurements' dependency on the location of the tracking markers mitigates systematic errors attributable to clubhead geometry or human error (in cases where tracking markers need to be re-applied). 
Table 4: Mean and standard deviation (SD) clubhead presentation for shots without tape $(\mathrm{n}=12)^{1}$.

\begin{tabular}{lllllllllll}
\hline & $\begin{array}{l}\text { Clubhead } \\
\text { speed } \\
\text { (mph) }\end{array}$ & $\begin{array}{l}\text { Clubhead } \\
\text { speed CG } \\
\text { (mph) }\end{array}$ & $\begin{array}{l}\text { Face } \\
\text { angle }\end{array}$ & $\begin{array}{l}\text { Path } \\
\text { CG }\end{array}$ & & & $\begin{array}{l}\text { Eff. } \\
\text { loft }\end{array}$ & $\begin{array}{l}\text { Attack } \\
\text { angle }\end{array}$ & $\begin{array}{l}\text { Attack } \\
\text { angle } \\
\text { CG }\end{array}$ & $\begin{array}{l}\text { Eff. } \\
\text { lie }\end{array}$ \\
\hline 5 iron & & & & & & & & & \\
\hline Mean 88.37 & 91.06 & 2.31 & 2.51 & 2.78 & 21.17 & -2.77 & -2.89 & 0.26 \\
SD & 0.11 & 0.52 & 0.16 & 0.04 & 0.07 & 0.46 & 0.07 & 0.04 & 0.24 \\
\hline 9 iron & & & & & & & & & \\
\hline Mean 85.19 & 87.48 & 3.11 & 2.98 & 2.95 & 36.72 & -4.13 & -4.12 & -0.42 \\
SD & 0.06 & 0.20 & 0.07 & 0.07 & 0.10 & 0.13 & 0.09 & 0.09 & 0.30 \\
\hline
\end{tabular}

${ }^{1}$ Impact location was aligned with the CG in the face coordinate system. Both CG and markerbased measurements have been presented for relevant measures. All values in degrees $\left(^{\circ}\right)$ unless stated otherwise.

Offsets between the optical system and the impact tape for horizontal impact position were minor, whereas systematic offsets were observed for vertical impact position as shown on Table 5. The positive 'error' values indicate that the centre of the mark left by the ball on the tape was, on average, higher on the face and towards the heel relative to the impact location reported by the clubhead tracking system for both clubs. As noted above, this 'error' could be described as an offset between two quantities, but for consistency with the horizontal error, the authors shall retain this nomenclature. The horizontal error values for both clubs are very small and likely to be a realistic indication of measurement error. Both values are lower than previous mean differences reported for a similar validation exercise of the system for use with drivers, ${ }^{8}$ although it should be reiterated that the convex face of drivers makes the calculation more complex, relative to the flat face of iron clubs. 
The vertical error was much larger for the 5-iron relative to the values of horizontal error, and larger still for the 9-iron. At this point, it becomes apparent that the two systems are measuring different quantities associated with the impact event between club and ball. The clubhead tracking system tracks the clubhead until the last frame prior to impact, and extrapolates the position of the clubface to the point at which it intersects the surface of the ball, and thus represents the point of first contact between club and ball. The centre of the imprint left on the tape, however, represents the centre of the contact area between club and ball. Golf balls have been shown to slide and then sometimes roll up the club face as a result of the loft of the face ${ }^{13}$. This provides an explanation for the discrepancy between the two measurement techniques in these higher lofted clubs. This observation was not noted during previous driver validations, ${ }^{8}$ which is likely due to the lower loft of the drivers tested.

Table 5: Comparison of clubhead tracking and tape-based measurements (mean \pm SD). ${ }^{1}$

\begin{tabular}{lll}
\hline Club & Horizontal error $(\mathrm{mm})$ & Vertical error $(\mathrm{mm})$ \\
\hline 5-iron & $0.12 \pm 0.43$ & $1.94 \pm 0.53$ \\
9-iron & $0.57 \pm 0.39$ & $3.66 \pm 0.54$ \\
\hline
\end{tabular}

${ }^{1}$ Errors calculated as the clubhead tracking system impact location subtracted from the tape impact location. A positive value indicates that the tape measurement was, on average, higher on the face and very slightly towards the heel than that of the clubhead tracking system. 
Table 6: Constants for linear trendlines fitted to vertical error in terms of vertical impact location in the clubhead tracking system (Fig. 7), such that error vertical $=\mathrm{My}+\mathrm{c}$, where $\mathrm{y}$ is vertical impact location measured by the tracking system.

\begin{tabular}{lll}
\hline Club & $M$ & $c$ \\
\hline 5-iron & -0.026 & 1.80 \\
9-iron & 0.004 & 3.64 \\
\hline
\end{tabular}

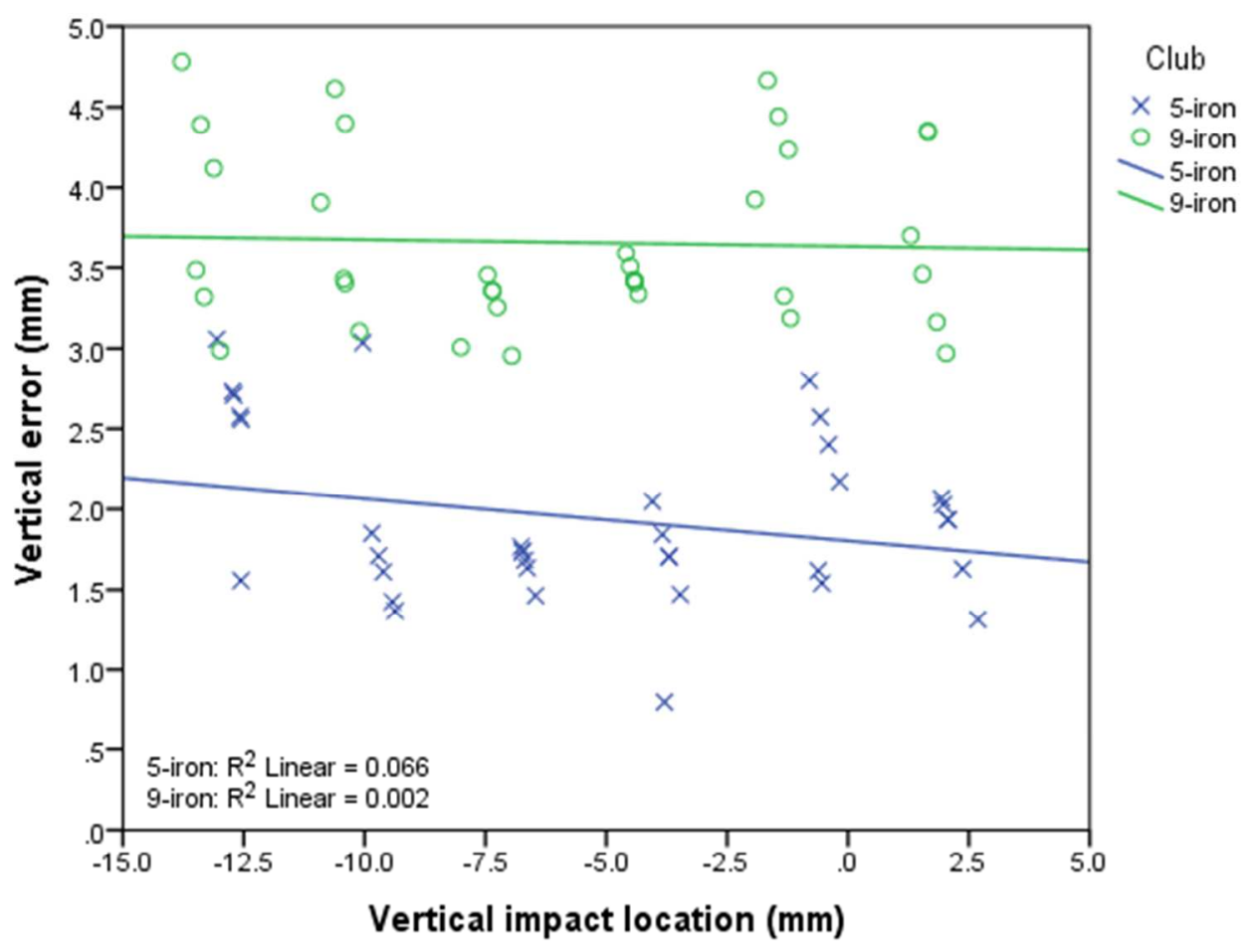

Figure 7: Vertical error plotted against vertical impact location as measured by the clubhead tracking system for both 5-iron and 9-iron tests.

Assuming the causal link between vertical error and loft to be true, it seems reasonable to expect some sort of proportionality between the two. Using the constant terms of the fitted trendlines as shown on Table 6 to approximate the component of error attributable to club loft enables correction of this effect; this step yields mean vertical errors of 0.14 and $0.02 \mathrm{~mm}$ for 5- and 9-irons, respectively. 
Whilst these results appear to be very positive in terms of validating the clubhead tracking system's measurement of impact location for iron shots, the two techniques of measuring impact location use different resolutions. The tape imprint was measured optically to the nearest millimetre, whilst the clubhead tracking system measured to a much higher resolution; although this needs to be considered in the context of residuals within the marker determination. As such, the repeatability of such a test could be questioned due to this discrepancy in resolution, particularly in terms of verifying submillimetre levels of accuracy, and therefore a more pragmatic quantification of measurement error would perhaps be closer to $\pm 1 \mathrm{~mm}$.

\section{Conclusion}

This article describes the validation of a novel clubhead tracking system previously used with drivers ${ }^{8}$ which was modified to be compatible with iron clubs, whilst simultaneously advancing the system to incorporate CG-based measurements and information regarding the position of the leading edge of the club face at impact. Using a golf robot, ball impact location using a conventional impact location technique and this novel tracking system were compared for swings with a 5-iron and a 9-iron.

Good agreement was shown in the horizontal direction (i.e. parallel to the grooves) between the impact location from the novel tracking system and the tape, but an offset was noted in the vertical direction (i.e. perpendicular to the grooves). This offset appeared to demonstrate reasonable proportionality with the irons' effective loft, and is considered to be the result of the ball travelling up the inclined plane of the face during 
impact. As such, a component of the vertical discrepancy between the clubhead tracking system and the reference measurement (centre of the imprint left on the club face by the ball) appears to be attributable to subtle differences in the nature of the impact location measured by each system. Hence, this tracking system is considered to be a novel solution to accurately locate the initial ball impact location on an iron clubhead.

\section{Funding}

This research received no specific grant from any funding agency in the public, commercial, or not-for-profit sectors.

\section{References}

1. Broadie M. Assessing Golfer Performance Using Golfmetrics. In: Crews D and Lutz R, (eds.). Proceedings of the World Scientific Congress of Golf. Mesa, Arizona: Energy in Motion, 2008, pp. 253-62.

2. Broadie M. Every shot counts: using the revolutionary strokes gained approach to improve your golf performance and strategy. New York: Gotham, 2014.

3. Broadie M. Putts Gained - Measuring Putting on the PGA TOUR, http://www.columbia.edu/ mmb2/broadie/research_golf.html (2011, accessed 10 August 2015).

4. Fearing D, Acimovic J and Graves SC. How to Catch a Tiger: Understanding Putting Performance on the PGA TOUR. Journal of Quantitative Analysis in Sports. 2011; 7. DOI: 10.2202/1559-0410.1268.

5. Williams KR and Sih BL. Changes in golf clubface orientation following impact with the ball. Sports Engineering. 2002; 5: 65-80. DOI: 10.1046/j.14602687.2002.00093.x.

6. Collinson AR, Wood P, Mullineaux DR and Willmott AP. The clubhead swing plane in golf draw and fade shots. In: BASES Biomechanics Interest Group Meeting, Belfast, U.K., 4th April 2012. Belfast: University of Ulster.

7. Sweeney M, Mills P, Alderson J and Elliott B. The influence of club-head kinematics on early ball flight characteristics in the golf drive. Sports Biomechanics. 2013; 12: 247-58. DOI: 10.1080/14763141.2013.772225.

8. Betzler NF, Monk SA, Wallace ES and Otto SR. Variability in clubhead presentation characteristics and ball impact location for golfers' drives. Journal of Sports Sciences. 2012; 30: 439-48. DOI: 10.1080/02640414.2011.653981. 
9. Corke TW, Betzler NF, Wallace ES and Otto SR. Clubhead presentation and spin control capability of elite golfers. Procedia Engineering. 2013; 60: 136-42. DOI: 10.1016/j.proeng.2013.07.012.

10. Cochran A and Stobbs J. The search for the perfect swing. London: Heinemann, 1968.

11. Cross R. The polar moment of inertia of striking implements. Sports Technology. 2010; 3: 215-9. DOI: 10.1080/19346182.2011.564287.

12. McCloy AJ, Wallace ES and Otto SR. Iron golf club striking characteristics for male elite golfers. In: Moritz EF and Haake S, (eds.). The Engineering of Sport 6. New York: Springer, 2006, pp. 353-8.

13. Arakawa K, Mada T, Komatsu H, et al. Dynamic contact behavior of a golf ball during an oblique impact. Experimental Mechanics. 2006; 46: 691-7. DOI.

14. Corke, TW Performance differences between blade and cavity back irons within the context of short-term player variation $2015 \mathrm{PhD}$ thesis Ulster 